Int. J. Electrochem. Sci., 14 (2019) $8907-8918$

\title{
Porous Carbon derived from Pine Nut Shell prepared by Steam Activation for Supercapacitor Electrode Material
}

\author{
Liyuan Qin ${ }^{1}$, Zhiwei Hou ${ }^{1}$, Shuang Lu ${ }^{1}$, Shuang Liu ${ }^{1}$, Zhongyuan Liu ${ }^{1}$, Enchen Jiang ${ }^{1,2, *}$ \\ ${ }^{1}$ College of Engineering, Northeast Agricultural University, Harbin, 130025, China \\ ${ }^{2}$ College of Materials and Energy, South China Agricultural University, Guangzhou, 510642, China \\ *E-mail: qinliyuan2006@163.com (L.Qin), enchenjiang@ hotmail.com (E. Jiang)
}

doi: $10.20964 / 2019.09 .20$

Received: 9 April 2019 / Accepted: 27 Jue 2019 / Published: 31 July 2019

\begin{abstract}
Porous activated carbon (AC) is prepared by the steam activation of biochar prepared from pyrolyzed pine nut shell as a precursor. The effects of various activation temperatures, activation times and steam flow rates on the structure and properties of the obtained ACs are compared and analyzed. The cyclic voltammetry, galvanostatic charge/discharge, electrochemical impedance spectroscopy and cycle stability properties of the ACs are measured in a three-electrode electrochemical system with $6 \mathrm{~mol} \mathrm{~L}^{-1}$ $\mathrm{KOH}$ solution as the electrolyte. The results show that an activation temperature of $850^{\circ} \mathrm{C}$, an activation time of $60 \mathrm{~min}$ and a steam flow rate of $18 \mathrm{ml} \mathrm{h}^{-1}$ are the optimal conditions. The AC obtained under these conditions displays a specific surface area of $956 \mathrm{~m}^{2} \mathrm{~g}^{-1}$, a mesopore ratio of $37.1 \%$ and a specific capacitance of $128 \mathrm{~F} \mathrm{~g} \mathrm{~g}^{-1}$ at $0.5 \mathrm{~A} \mathrm{~g}^{-1}$. Moreover, the AC has a well-developed interconnected hierarchical pore structure including micropores, mesopores and macropores and a good capacitance retention rate of $98 \%$ at a current density of $5 \mathrm{~A} \mathrm{~g}^{-1}$ after 10000 cycles of testing. These high-performance ACs from biomass waste show potential industrial applications in energy storage.
\end{abstract}

Keywords: pine nut shell; hierarchical porous carbon; steam activation; supercapacitor electrode

\section{FULL TEXT}

(C) 2019 The Authors. Published by ESG (www.electrochemsci.org). This article is an open access article distributed under the terms and conditions of the Creative Commons Attribution license (http://creativecommons.org/licenses/by/4.0/). 